\title{
Optimization of a Protocol for the Cryopreservation of Sperm in Pellets for the Common Pheasant (Phasianus colchicus mongolicus)
}

\author{
Annelisse Castillo ${ }^{1}$, Carla Lenzi ${ }^{2}$, Andrea Pirone ${ }^{2}$, Alessandro Baglini ${ }^{2}$, Silvia Cerolini ${ }^{3}$ (D), \\ Nicolaia Iaffaldano ${ }^{4}\left(\mathbb{D}\right.$, Stefano Sartore ${ }^{1}\left(\mathbb{D}\right.$, Claudia Russo $^{2}$, Achille Schiavone ${ }^{1, *(\mathbb{D})}$ \\ and Margherita Marzoni Fecia di Cossato ${ }^{2}$
}

Citation: Castillo, A.; Lenzi, C.; Pirone, A.; Baglini, A.; Cerolini, S.; Iaffaldano, N.; Sartore, S.; Russo, C.; Schiavone, A.; Marzoni Fecia di Cossato, M. Optimization of a Protocol for the Cryopreservation of Sperm in Pellets for the Common Pheasant (Phasianus colchicus mongolicus). Animals 2021, 11, 2472. https://doi.org/10.3390/ani11082472

Academic Editor: Roy

Neville Kirkwood

Received: 19 July 2021

Accepted: 23 August 2021

Published: 23 August 2021

Publisher's Note: MDPI stays neutral with regard to jurisdictional claims in published maps and institutional affiliations.

Copyright: (c) 2021 by the authors. Licensee MDPI, Basel, Switzerland. This article is an open access article distributed under the terms and conditions of the Creative Commons Attribution (CC BY) license (https:// creativecommons.org/licenses/by/ $4.0 /)$.
1 Dipartimento di Scienze Veterinarie, Università degli Studi di Torino, Largo Paolo Braccini 2, 10095 Grugliasco, Italy; annelisse.castillogarrido@unito.it (A.C.); stefano.sartore@unito.it (S.S.)

2 Dipartimento di Scienze Veterinarie, Università di Pisa, Viale delle Piagge 2, 56124 Pisa, Italy; carla.lenzi@unipi.it (C.L.); andrea.pirone@unipi.it (A.P.); alessandro.baglini@unipi.it (A.B.); claudia.russo@unipi.it (C.R.); margherita.marzoni@unipi.it (M.M.F.d.C.)

3 Dipartimento di Medicina Veterinaria, Università degli Studi di Milano, Via dell'Università 6, 26900 Lodi, Italy; silvia.cerolini@unimi.it

4 Dipartimento Agricoltura, Ambiente e Alimenti, Università degli Studi del Molise, Via Francesco De Sanctis, 86100 Campobasso, Italy; nicolaia@unimol.it

* Correspondence: achille.schiavone@unito.it; Tel.: +39-011-670-9208

Simple Summary: The cryopreservation of avian semen is currently used to preserve species, breeds, and breeding lines. Bird sperm have unique characteristics, and each species responds differently to the freezing-thawing process; in this context, little information about the cryopreservation of the semen of the common pheasant is available. In this study, we tested different parameters at each step of the process of freezing into pellets and thawing with the aim of detecting the least deleterious parameter settings. The pheasant sperm exhibited a high susceptibility to the damage caused by the process of freezing into pellets; however, the survival rate of the sperm was $29 \%$, and the greatest recovered mobility was $22 \%$. The mobility of the sperm was affected by the dilution and the concentration of the dimethylacetamide cryoprotectant; the viability of the sperm was affected by both the equilibration at $5{ }^{\circ} \mathrm{C}$ and the dimethylacetamide equilibration. The protocols that caused the least damage to the pheasant sperm were found to be those with higher dilution rates, $10 \mathrm{~min}$ of equilibration at $5{ }^{\circ} \mathrm{C}$ and equilibration of $6 \%$ dimethylacetamide for 1 or $5 \mathrm{~min}$. In the present study, we individualise some applicable parameters for certain critical steps of the freezing-thawing process; however, further investigations are needed in order to improve upon and complete a suitable protocol for the cryopreservation and thawing of pheasant sperm.

Abstract: The sperm of each avian species and breed have unique characteristics that render them more or less susceptible to the freezing-thawing process; therefore, a suitable cryopreservation protocol that is specific for the sperm of each type of bird is needed. In this context, little information about the common pheasant's sperm is available. Therefore, the aim of this study was to test different parameters at each step of the process of freezing into pellets and thawing to detect the least deleterious parameter settings. Sixteen different protocols were tested by studying two levels in each of the four steps (dilution, equilibration at $5{ }^{\circ} \mathrm{C}$, final dimethylacetamide concentration, and dimethylacetamide equilibration time) comprising the freezing process. The pheasant sperm exhibited a high susceptibility to the damage caused by freezing into pellets; however, the survival of the sperm reached $29 \%$, and the greatest recovered mobility was $22 \%$. The mobility of the sperm was affected by the dilution and the dimethylacetamide concentration, and the viability of the sperm was affected by the equilibration at $5{ }^{\circ} \mathrm{C}$ and the dimethylacetamide equilibration. The protocols that caused the least damage to the pheasant sperm were found to be those with higher dilution rates, $10 \mathrm{~min}$ of equilibration at $5{ }^{\circ} \mathrm{C}$, and $6 \%$ dimethylacetamide equilibrated for 1 or $5 \mathrm{~min}$. In the present study, we individualise some applicable parameters for certain critical steps of the freezing-thawing 
process; however, further investigations are needed in order to improve upon and complete a suitable protocol for the cryopreservation and thawing of pheasant sperm.

Keywords: pheasant semen; freezing process; DMA; pellets

\section{Introduction}

The ability of avian sperm to survive the freezing-thawing process and to remain functional differs not only among species or breeds [1], but even among individuals [2-4]. Several factors may contribute to the success of the cryopreservation of sperm, such as the birds' breeding conditions, the semen collection procedure, the freezing-thawing protocol, etc. [1].

The freezing-thawing process comprises different critical steps, which begin with a diluent and its concentration. The diluent should offer the sperm a suitable environment in terms of $\mathrm{pH}$, osmolality, electrolyte composition, nourishment, protection, etc. in order to face the stresses of the freezing-thawing process [1-5]. The diluent concentration is also crucial; it should provide the cells with enough space and access to oxygen and substrates, as well as space for the metabolic waste $[1,5,6]$.

Additional key factors that influence the success of the cryopreservation process are the cryoprotectant, its concentration, its combination with the cooling rate, and its equilibration time $[1,4,7]$. Cryopreservation is the use of extremely low temperatures to preserve intact and living cells and tissues [8], but very low temperatures cause freezing damage to cells if they are not protected [1,4]. Freezing injuries might be provoked by the freezing of water, which forms ice crystals that are able to pierce the cells, or damage may be caused by changes in the lipid composition of the cell membrane $[8,9]$. To prevent these negative effects, cells must be protected by a "cryoprotectant". The cryoprotectant is characterised by its ability to penetrate cells and all parts of the system, thus reducing the amount of ice that can be formed. Another characteristic of a cryoprotectant is that it must have a low toxicity for the cell [8]. The cryoprotectant acts by increasing the total concentration of all solutes in the system, even if numerous barriers (for example, membranes) are encountered that impede the free diffusion of solutes during the penetration into the cells. This situation may cause osmotic fluctuations, resulting in important effects throughout the various steps of the freezing-thawing process [8-10].

The next step of the cryopreservation process is the freezing method, which may be slow or more rapid, and the packaging into pellets or straws. Finally, the last parts of the process are the thawing method and temperature of thawing [1]. For all of the factors mentioned above, specific cryopreservation protocols are needed for each species or breed [11]. In birds, several studies have described different protocols for various domestic and non-domestic birds $[1,4,12-16]$. Among these, semen from a few wild pheasant species was also cryopreserved $[17,18]$. According to the Convention on International Trade in Endangered Species of Wild Fauna and Flora, nineteen species of the Phasianidae family are included in Appendix I as the most endangered [19]. The greatest ex situ populations of bird species that can breed in captivity are kept by zoos [17]. In this context, sperm cryopreservation technology might be useful; in particular, the common pheasant might be used as a model that can be applied to Phasianidae species. In the past, some in vitro aspects of the freezing-thawing process were studied in our laboratory [20-22], in addition to the in vivo response of sperm after being thawed [23,24], the hatchability of pheasant eggs fertilised with thawed sperm [25], and the bird-breeding conditions for collecting high-quality ejaculate [26]. However, for the semen of the common pheasant, there is still very little information regarding its cryopreservation. Therefore, the aim of this study was to test different parameters at the various steps of the freezing-thawing process in order to determine the least deleterious parameter settings for the pheasants' sperm. 


\section{Materials and Methods}

\subsection{Experimental Design}

The model used for the freezing-thawing $(\mathrm{F}-\mathrm{T})$ protocol for the pheasant semen had a $2 \times 2 \times 2 \times 2$ design: dilution (1:2 or 1:3), equilibration at $5^{\circ} \mathrm{C}\left(10^{\prime}\right.$ or $\left.30^{\prime}\right)$, dimethylacetamide (DMA) concentration ( $6 \%$ or $9 \%)$, and DMA equilibration time $\left(1^{\prime}\right.$ or $\left.5^{\prime}\right)$. All of the combinations of these factors were applied in the F-T process.

\subsection{Reagents}

All chemicals were purchased from Sigma-Aldrich Chemical Co., Milan, Italy. Accudenz was purchased from Accurate Chemical and Scientific Corp., Westbury, NY, USA.

\subsection{Birds}

Thirty common male pheasants (Phasianus colchicus mongolicus) in their first reproductive season were housed in a peaceful location far from crosswalks in open-air aviaries with perches; each male had a $6 \mathrm{~m}^{2}$ space [26]. The birds were fed ad libitum on a standard commercial feed (11.51 MJ/kg of M.E., $19 \%$ of C.P.). The trial lasted 45 days and began in the middle of April. The males were trained for semen collection for two weeks prior to beginning the trial.

\subsection{Semen Processing}

Semen was collected by using the dorso-abdominal massage technique [27], which was slightly modified to obtain each bird's spontaneous cloaca eversion and the ejaculation, as described by Castillo et al. [28]. Briefly, two operators were needed. The first operator used both hands to massage and stimulate the bird; the second one collected the ejaculate by means of a pipette. At 3-day intervals, twenty to twenty-five ejaculates of good quality were collected per sampling time. In each week of the trial, one day of semen sampling was set aside for the study (a total of 6 days).

Semen was collected from each male and directly introduced into a collection tube with $50 \mu \mathrm{L}$ of Lake's diluent [29]. Immediately thereafter, it was placed inside a portable refrigerator at $18{ }^{\circ} \mathrm{C}$ while waiting until all donors were done. Only dense, milky white ejaculates were chosen for analysis and processing, and those with an uncharacteristic colour and/or fluidity were rejected. The ejaculate volume was assessed by weighing the tubes before and after collection (Sartorius BL $150 \mathrm{~S} \pm 0.001 \mathrm{~g}$ ). The semen was pooled, and an aliquot was taken to assess the quality of the fresh semen. The sperm concentration was assessed in duplicate with a Bürker-Türk counting chamber (in 5\% formalin and $0.9 \%$ $\mathrm{NaCl}$ solution) [30]. The percentage of viable sperm was evaluated on 500 cells in triplicate through eosin-nigrosin staining [31]. Viable cells were not stained at all; cells that were considered dead appeared totally or partly stained pink. The percentage of viable sperm was calculated based on the sperm count. Sperm mobility was assessed in triplicate with the Accudenz methodology [32]. The mobility, as opposed to the ability of the sperm to move (motility), is the ability of the cell to penetrate a viscous medium with a temperature of $41^{\circ} \mathrm{C}$, and this penetration was measured with a spectrophotometer at an absorbance of $550 \mathrm{~nm}$ [32].

\subsection{Methodology of Freezing into Pellets}

The semen was frozen with the pellet methodology [33]. Sixteen different protocols were tested by combining two variants in each of the four steps (dilution, equilibration at $5{ }^{\circ} \mathrm{C}$, final DMA concentration, and equilibration time with the DMA) comprising the freezing process. The pooled semen was divided into two aliquots and diluted at a ratio of 1:2 or 1:3 (v/v) in Lake's diluent [29] (dilution $=\mathrm{D}$ ). Diluted pools were then divided into $350 \mu \mathrm{L}$ aliquots and rapidly cooled to reach a temperature of $5{ }^{\circ} \mathrm{C}$; they were kept in this condition for exactly $10 \mathrm{~min}$ or $30 \mathrm{~min}$ (equilibration at $5{ }^{\circ} \mathrm{C}=\mathrm{Eq} 5{ }^{\circ} \mathrm{C}$ ). Thereafter, the $5^{\circ} \mathrm{C}$ DMA cryoprotectant, which was at a final concentration of $6 \%$ or $9 \%$ (DMA), was added, mixed manually for one minute in an ice-water bath, and allowed to equilibrate for 1 or 
5 min inside the bath (equilibration with DMA = EqDMA). The semen was then frozen by dropping it from a height of $20 \mathrm{~cm}$ into a liquid nitrogen bath. The drop volume used was $80 \mu \mathrm{L}$. The pellets were grouped by protocol and stored in cryovials containing 6-7 pellets each. The pellets were thawed by placing one pellet at a time onto a hotplate at $50^{\circ} \mathrm{C}$ [22]

\subsection{Thawed Sperm Quality}

The qualitative parameters recorded in the frozen-thawed (F-T) sperm were the following: the percentage of viable sperm was evaluated on 100 cells in triplicate through eosin-nigrosin staining [30] and was calculated based on the consideration of the thawed cells as $100 \%$. From the live F-T sperm, normal cells were detected, and their percentage was calculated with respect to the viable F-T cells. Within the portion of live F-T sperm, cells were grouped according to lesions in their head or tail. The head injuries were grouped according to if they were bent, fractured, coiling, swollen/detached, knotted, and lacking a tail. The tail injuries identified were looping, coiling, and lacking a head; these data are reported as the percentage of live F-T sperm. Sperm mobility was assessed by following the same procedure as that reported for the fresh sperm [32]. The mobility is reported as the absorbance units at $550 \mathrm{~nm}$, and the recovered mobility is expressed as the percentage of fresh sperm mobility.

\subsection{Statistical Analysis}

The results are presented as the mean \pm standard deviation (SD). All analyses were performed at a significance level of $p<0.05$ using JMP Statistical Discovery (SAS Institute Inc., Cary, NC, USA, v. 5.0.1.). The percentage data were normalised through $\sqrt{ } \mathrm{x}$ arcsine transformation. The parameters of the fresh semen obtained on the six collection days were analysed using a one-way ANOVA, followed by Tukey's test for comparison of means. The following general linear model was used:

$$
Y_{i j}=\mu+\alpha_{i}+\varepsilon_{i j}
$$

where $Y_{i j}$ is the observation, $\mu$ is the overall mean, $\alpha_{i}$ is the fixed effect of the $\mathrm{i}^{\text {th }}$ day of collection ( $\mathrm{i}=1$ to 6 ), and $\varepsilon_{\mathrm{ij}}$ is the random error.

To determine the effects of dilution, Eq5 ${ }^{\circ} \mathrm{C}$, DMA, and EqDMA on the sperm variables, the data were analysed using a four-factor ANOVA, followed by Tukey's test for comparison of means. After running the full model, a custom model was set up to exclude all of the interaction terms that were not significant and of no interest. The following general linear model was used:

$$
\mathrm{Y}_{\mathrm{ijklm}}=\mu+\alpha_{\mathrm{i}}+\beta_{\mathrm{j}}+\gamma_{\mathrm{k}}+\delta_{\mathrm{l}}+(\alpha \beta)_{\mathrm{ij}}+(\alpha \beta \gamma)_{\mathrm{ijk}}+(\alpha \beta \gamma \delta)_{\mathrm{ijkl}}+\varepsilon_{\mathrm{ijklm}}
$$

where $Y_{\mathrm{ijklm}}$ is the dependent sperm variable, $\mu$ is the overall mean, $\alpha_{\mathrm{i}}$ is the fixed effect of dilution ( $\mathrm{i}=1: 2,1: 3), \beta_{\mathrm{j}}$ is the fixed effect of Eq5 ${ }^{\circ} \mathrm{C}\left(\mathrm{j}=10^{\prime}, 30^{\prime}\right), \gamma_{\mathrm{k}}$ is the fixed effect of DMA $(\mathrm{k}=6 \%, 9 \%), \delta_{1}$ is the fixed effect of EqDMA $\left(1=1^{\prime}, 5^{\prime}\right),(\alpha \beta)_{\mathrm{ij}}$ is the fixed effect of the interaction between dilution and $\mathrm{Eq} 5{ }^{\circ} \mathrm{C},(\alpha \beta \gamma)_{\mathrm{ijk}}$ is the fixed effect of the interaction between dilution, Eq5 ${ }^{\circ} \mathrm{C}$, and DMA, $(\alpha \beta \gamma \delta)_{\mathrm{ijk}}$ is the effect of the interaction between dilution, $\mathrm{Eq} 5{ }^{\circ} \mathrm{C}, \mathrm{DMA}$, and $\mathrm{EqDMA}$, and $\varepsilon_{\mathrm{ijk} k m}$ is the random error.

\section{Results}

The day of collection did not affect the quality parameters of the fresh semen; the following values were recorded: The mean ejaculation volume was $135 \pm 13 \mu \mathrm{L}$, the mean sperm concentration was $12.408 \pm 1.08 \times 10^{9} / \mathrm{mL}$, the mean viability was $91.4 \pm 1.98 \%$, and the mean mobility was $0.206 \pm 0.0025$ absorbance units. Compared to the fresh sperm, the thawed sperm showed a significant loss in both viability (between $79.8 \%$ and $98.5 \%$, $p<0.01$ ) and mobility (between $85.2 \%$ and $95.7 \%, p<0.01$ ).

Table 1 reports the quality parameters of the frozen pheasant semen according to the effects of the parameters at each step of the freezing procedure. The effects of the two 
dilution levels were significantly higher in the more diluted samples for both variablesnamely, the mobility $(p<0.01)$ and the recovered mobility $(p<0.05)$. The percentage of live sperm was statistically higher when the Eq5 ${ }^{\circ} \mathrm{C}$ lasted 10 min rather than $30 \mathrm{~min}(p<0.01)$. A difference due to the cryoprotectant was observed in the mobility, which was more favourable with the lower concentration $(6 \%, p<0.01)$. A longer EqDMA turned out to be more advantageous for the percentage of live sperm $(p<0.01)$.

Table 1. Effect on the quality parameters of common pheasant sperm that was frozen using two levels in each step (dilution rate, equilibration at $5{ }^{\circ} \mathrm{C}$, DMA concentration, equilibration time with DMA) of the process of freezing into pellets (means $\pm \mathrm{SD}$ ).

\begin{tabular}{|c|c|c|c|c|c|}
\hline & & Viability (\%) & Normal (\%) & Mobility Abs ${ }^{5}$ & $\begin{array}{r}\text { Recovered } \\
\text { Mobility (\%) }\end{array}$ \\
\hline \multirow{2}{*}{$\mathrm{D}^{1}$} & $1: 2$ & $15.4 \pm 7.25$ & $29.9 \pm 7.26$ & $0.0150 \pm 0.007^{\mathrm{B}}$ & $15.0 \pm 3.66^{B}$ \\
\hline & $1: 3$ & $15.2 \pm 6.66$ & $29.2 \pm 5.93$ & $0.0234 \pm 0.012^{\mathrm{A}}$ & $18.0 \pm 6.07^{\mathrm{A}}$ \\
\hline \multirow{2}{*}{$\mathrm{Eq} 5^{\circ} \mathrm{C}^{2}$} & 10 & $17.2 \pm 7.15^{\mathrm{A}}$ & $29.6 \pm 6.64$ & $0.0204 \pm 0.011$ & $17.4 \pm 5.22$ \\
\hline & 30 & $12.8 \pm 5.64^{\mathrm{B}}$ & $29.4 \pm 6.44$ & $0.0180 \pm 0.008$ & $15.5 \pm 5.20$ \\
\hline \multirow{2}{*}{$\mathrm{DMA}^{3}$} & 6 & $15.5 \pm 6.71$ & $30.6 \pm 6.26$ & $0.0227 \pm 0.011^{\mathrm{a}}$ & $17.5 \pm 5.51$ \\
\hline & 9 & $15.1 \pm 7.18$ & $28.1 \pm 6.66$ & $0.0157 \pm 0.008^{b}$ & $15.6 \pm 4.85$ \\
\hline \multirow{2}{*}{$\mathrm{Eq}^{4}$} & 1 & $13.2 \pm 6.55^{\mathrm{B}}$ & $28.3 \pm 7.64$ & $0.0199 \pm 0.011$ & $17.1 \pm 5.14$ \\
\hline & 5 & $16.7 \pm 6.79^{\mathrm{A}}$ & $30.3 \pm 5.63$ & $0.0186 \pm 0.010$ & $16.3 \pm 5.38$ \\
\hline \multicolumn{6}{|l|}{ Effect } \\
\hline $\mathrm{D}$ & & $p=0.8850$ & $p=0.9052$ & $p=0.0055$ & $p=0.0213$ \\
\hline $\mathrm{Eq} 5^{\circ} \mathrm{C}$ & & $p=0.0038$ & $p=0.8666$ & $p=0.3480$ & $p=0.3832$ \\
\hline DMA & & $p=0.5444$ & $p=0.5094$ & $p=0.0069$ & $p=0.0994$ \\
\hline $\mathrm{Eq}$ & & $p=0.0070$ & $p=0.1702$ & $p=0.6182$ & $p=0.6175$ \\
\hline $\mathrm{D}^{*} \mathrm{Eq} 5^{\circ} \mathrm{C}$ & & $p=0.8046$ & $p=0.8769$ & $p=0.9165$ & $p=0.9856$ \\
\hline $\mathrm{D}^{*} \mathrm{Eq} 5^{\circ} \mathrm{C}^{*} \mathrm{DMA}$ & & $p=0.0625$ & $p=0.6226$ & $p=0.2098$ & $p=0.2443$ \\
\hline $\mathrm{D}^{*} \mathrm{Eq} 5^{\circ} \mathrm{C}^{*} \mathrm{DMA}{ }^{*} \mathrm{Eq}$ & & $p=0.5106$ & $p=0.7744$ & $p=0.5194$ & $p=0.5479$ \\
\hline
\end{tabular}

${ }^{1}$ dilution $(v / v) ;{ }^{2}$ equilibration at $5{ }^{\circ} \mathrm{C}$ (minutes); ${ }^{3}$ dimethylacetamide $(\%) ;{ }^{4}$ equilibration time with DMA (minutes). ${ }^{5}$ absorbance units at $550 \mathrm{~nm} .{ }^{\mathrm{A}, \mathrm{B}}$ Means within a column of each step of the freezing process with different superscripts are significantly different $(p<0.01) .{ }^{\mathrm{a}, \mathrm{b}}$ Means within a column of each step of the freezing process with different superscripts are significantly different $(p<0.05)$.

The combinations of the two variants in each of the four steps (dilution, Eq $5^{\circ} \mathrm{C}, \mathrm{DMA}$, and EqDMA) of the F-T process resulted in sixteen different protocols that were tested (Table 2).

Table 2. Quality parameters of the common pheasant sperm that was cryopreserved according to 16 freezing protocols that differed according to the two levels employed in each step (dilution, equilibration at $5{ }^{\circ} \mathrm{C}$, DMA concentration, equilibration time with DMA) of the freezing process (means $\pm \mathrm{SD}$ ).

\begin{tabular}{|c|c|c|c|c|c|c|c|}
\hline$D^{1}$ & $\begin{array}{l}N \\
u \\
0 \\
\text { in } \\
0 \\
1\end{array}$ & DMA $^{3}$ & $\mathrm{Eq}^{4}$ & Live (\%) & Normal (\%) & Mobility Abs ${ }^{5}$ & $\begin{array}{c}\text { Recovered } \\
\text { Mobility (\%) }\end{array}$ \\
\hline \multirow{4}{*}{$1: 2$} & \multirow{2}{*}{10} & 6 & $\begin{array}{l}1 \\
5\end{array}$ & $\begin{array}{c}7.1 \pm 3.2^{\mathrm{D}} \\
15.4 \pm 4.0^{\mathrm{CD}}\end{array}$ & $\begin{array}{c}22.5 \pm 10.6 \\
33.6 \pm 6.8\end{array}$ & $\begin{array}{c}0.020 \pm 0.000^{\mathrm{ABC}} \\
0.018 \pm 0.009^{\mathrm{C}}\end{array}$ & $\begin{array}{l}17.5 \pm 0.2^{\mathrm{abc}} \\
15.8 \pm 4.4^{\mathrm{bc}}\end{array}$ \\
\hline & & 9 & $\begin{array}{l}1 \\
5\end{array}$ & $\begin{array}{c}16.8 \pm 7.8^{\mathrm{BC}} \\
28.8 \pm 1.6^{\mathrm{A}}\end{array}$ & $\begin{array}{l}26.5 \pm 7.0 \\
32.6 \pm 1.4\end{array}$ & $\begin{array}{l}0.014 \pm 0.006^{\mathrm{C}} \\
0.013 \pm 0.005^{\mathrm{C}}\end{array}$ & $\begin{array}{l}14.2 \pm 3.2^{b c} \\
13.8 \pm 3.0^{b c}\end{array}$ \\
\hline & \multirow{2}{*}{30} & 6 & $\begin{array}{l}1 \\
5\end{array}$ & $\begin{array}{c}10.0 \pm 3.7^{C D} \\
14.6 \pm 10.2^{C D}\end{array}$ & $\begin{array}{c}26.8 \pm 11.9 \\
34.1 \pm 4.9\end{array}$ & $\begin{array}{c}0.009 \pm 0.007^{\mathrm{C}} \\
0.019 \pm 0.007^{\mathrm{BC}}\end{array}$ & $\begin{array}{c}11.5 \pm 4.7^{\mathrm{c}} \\
16.5 \pm 3.3^{\mathrm{abc}}\end{array}$ \\
\hline & & 9 & $\begin{array}{l}1 \\
5\end{array}$ & $\begin{array}{c}8.0 \pm 0.2^{\mathrm{D}} \\
16.3 \pm 3.2^{\mathrm{BCD}}\end{array}$ & $\begin{array}{l}23.8 \pm 8.8 \\
30.3 \pm 6.1\end{array}$ & $\begin{array}{l}0.009 \pm 0.001^{C} \\
0.017 \pm 0.008^{C}\end{array}$ & $\begin{array}{c}12.0 \pm 0.9^{c} \\
15.5 \pm 4.3^{b c}\end{array}$ \\
\hline
\end{tabular}


Table 2. Cont.

\begin{tabular}{|c|c|c|c|c|c|c|c|}
\hline$D^{1}$ & $\begin{array}{l}N \\
u \\
0 \\
i n \\
0 \\
01\end{array}$ & DMA $^{3}$ & $\mathrm{Eq}^{4}$ & Live (\%) & Normal (\%) & Mobility $_{\text {Ass }}{ }^{5}$ & $\begin{array}{c}\text { Recovered } \\
\text { Mobility (\%) }\end{array}$ \\
\hline \multirow{4}{*}{$1: 3$} & \multirow{2}{*}{10} & 6 & $\begin{array}{l}1 \\
5\end{array}$ & $\begin{array}{c}16.4 \pm 7.8^{\mathrm{BCD}} \\
20.7 \pm 5.2^{\mathrm{AB}}\end{array}$ & $\begin{array}{l}23.8 \pm 8.8 \\
29.7 \pm 5.8\end{array}$ & $\begin{array}{c}0.035 \pm 0.010^{\mathrm{A}} \\
0.032 \pm 0.010^{\mathrm{AB}}\end{array}$ & $\begin{array}{c}22.3 \pm 1.1^{\mathrm{a}} \\
21.6 \pm 3.8^{\mathrm{ab}}\end{array}$ \\
\hline & & 9 & $\begin{array}{l}1 \\
5\end{array}$ & $\begin{array}{c}10.2 \pm 4.4^{\mathrm{CD}} \\
19.2 \pm 8.1^{\mathrm{ABC}}\end{array}$ & $\begin{array}{c}29.6 \pm 12.0 \\
26.5 \pm 7.0\end{array}$ & $\begin{array}{l}0.015 \pm 0.011^{C} \\
0.017 \pm 0.013^{C}\end{array}$ & $\begin{array}{c}15.3 \pm 6.9^{c} \\
16.7 \pm 8.0^{a b c}\end{array}$ \\
\hline & \multirow{2}{*}{30} & 6 & $\begin{array}{l}1 \\
5\end{array}$ & $\begin{array}{c}17.6 \pm 5.7^{\mathrm{ABC}} \\
9.8 \pm 4.3^{\mathrm{D}}\end{array}$ & $\begin{array}{l}32.5 \pm 2.2 \\
28.6 \pm 5.4\end{array}$ & $\begin{array}{c}0.033 \pm 0.004^{\mathrm{AB}} \\
0.012 \pm 0.009^{\mathrm{C}}\end{array}$ & $\begin{array}{l}22.1 \pm 1.4^{\mathrm{a}} \\
11.2 \pm 7.7^{\mathrm{c}}\end{array}$ \\
\hline & & 9 & $\begin{array}{l}1 \\
5\end{array}$ & $\begin{array}{c}9.1 \pm 1.3^{\mathrm{CD}} \\
11.9 \pm 2.2^{\mathrm{CD}}\end{array}$ & $\begin{array}{c}29.6 \pm 13.6 \\
25.6 \pm 5.1\end{array}$ & $\begin{array}{c}0.022 \pm 0.006^{\mathrm{ABC}} \\
0.017 \pm 0.008^{\mathrm{C}}\end{array}$ & $\begin{array}{l}20.0 \pm 4.2^{a b c} \\
15.8 \pm 3.7^{a b c}\end{array}$ \\
\hline
\end{tabular}

1 dilution $(v / v) ;{ }^{2}$ equilibration at $5{ }^{\circ} \mathrm{C}$ (minutes); ${ }^{3}$ dimethylacetamide (\%); ${ }^{4}$ equilibration time with DMA (minutes). ${ }^{5}$ absorbance units at $550 \mathrm{~nm}$. A-D Means within a column of each step of the freezing process with different superscripts are significantly different $(p<0.01) .{ }^{\mathrm{a}-\mathrm{c}}$ Means within a column of each step of the freezing process with different superscripts are significantly different $(p<0.05)$.

Higher percentages of live sperm were mainly observed with higher dilution rates, $10 \mathrm{~min}$ of $\mathrm{Eq} 5^{\circ} \mathrm{C}$ and $5 \mathrm{~min}$ for the EqDMA, and the protocols that gave the best results were characterised by the following parameter levels: $1: 2-10^{\prime}-9 \%-5^{\prime}, 1: 3-10^{\prime}-6 \%$, or $9 \%-5^{\prime}$, 1:3-30' $-6 \%-1^{\prime}(p<0.01)$. The percentage of normal cells was not affected by the protocols. The sperm mobility was higher with the more diluted semen, a Eq $5{ }^{\circ} \mathrm{C}$ of $10 \mathrm{~min}, 6 \% \mathrm{DMA}$, and an EqDMA of 1 minute, and the protocols that gave the best results were characterised by the following parameter levels: $1: 3-10^{\prime}$ or $30^{\prime}-6 \%-1^{\prime}, 1: 3-10^{\prime}-6 \%-5^{\prime}, 1: 3-30^{\prime}-9 \%-1^{\prime}$, and $1: 2-10^{\prime}-6 \%-1^{\prime}(p<0.01)$. A higher recovered mobility was also observed with the higher dilution rate and with the $6 \%$ final DMA concentration, and the best results were characterised by the following parameter levels: $1: 3-10^{\prime}$ or $30^{\prime}-6 \%-1^{\prime}, 1: 3-10^{\prime}-6 \%-5^{\prime}, 1: 3-30^{\prime}-9 \%-1^{\prime}$, $1: 2-10^{\prime}-6 \%-1^{\prime}, 1: 3-10^{\prime}$ or $30^{\prime}-9 \%-5^{\prime}$, and $1: 2-30^{\prime}-6 \%-5^{\prime}$.

Tables 3 and 4 show the head and tail injuries in the pheasant sperm that were subjected to the freezing-thawing process. A difference was observed in the Eq5 ${ }^{\circ} \mathrm{C}$ step, which showed a higher number of sperm with bent heads for the value of $10 \mathrm{~min}$ (Table 3; $p<0.01$ ). In addition, the tail injuries were different with the same $\mathrm{Eq} 5{ }^{\circ} \mathrm{C}$, as coiling tails were more frequently observed (Table $4 ; p<0.05$ ). A higher incidence of looping tails (Table $4 ; p<0.01$ ) and sperm without tails was observed with 9\% DMA (Table $3 ; p<0.05$ ).

Table 3. Head injuries in frozen common pheasant sperm when using the two levels for each step (dilution, cooling rate, DMA concentration, equilibration time with DMA) of the freezing process in pellets and the step influence on the incidence of these damages (means $\pm \mathrm{SD}$ ).

\begin{tabular}{|c|c|c|c|c|c|c|c|}
\hline & & Bent & Fracture & Coiling & Swo-Det ${ }^{5}$ & Knotted & No Tail \\
\hline & \multicolumn{7}{|c|}{$(\%)$} \\
\hline \multirow{2}{*}{$\mathrm{D}^{1}$} & $1: 2$ & $0.99 \pm 1.75$ & $25.0 \pm 13.69$ & $0.3 \pm 1.17$ & $16.0 \pm 9.07$ & $1.5 \pm 1.97$ & $1.3 \pm 4.31$ \\
\hline & $1: 3$ & $1.31 \pm 2.12$ & $24.1 \pm 11.60$ & $0.5 \pm 2.63$ & $14.2 \pm 9.39$ & $0.7 \pm 1.43$ & $1.3 \pm 5.22$ \\
\hline \multirow{2}{*}{$\mathrm{Eq} 5{ }^{\circ} \mathrm{C}^{2}$} & 10 & $1.76 \pm 2.28^{\mathrm{A}}$ & $24.0 \pm 11.89$ & $0.6 \pm 2.76$ & $13.2 \pm 7.84$ & $1.0 \pm 1.53$ & $0.6 \pm 2.23$ \\
\hline & 30 & $0.41 \pm 1.07^{\mathrm{B}}$ & $25.2 \pm 13.34$ & $0.1 \pm 0.58$ & $17.3 \pm 10.43$ & $1.1 \pm 1.97$ & $2.2 \pm 6.76$ \\
\hline \multirow{2}{*}{$\mathrm{DMA}^{3}$} & 6 & $1.13 \pm 1.71$ & $24.0 \pm 12.62$ & $0.6 \pm 2.71$ & $15.4 \pm 10.03$ & $1.1 \pm 1.56$ & $0.2 \pm 0.95^{b}$ \\
\hline & 9 & $1.22 \pm 2.28$ & $25.2 \pm 12.46$ & $0.1 \pm 0.59$ & $14.5 \pm 8.16$ & $1.1 \pm 1.95$ & $2.7 \pm 7.12^{a}$ \\
\hline \multirow{2}{*}{$\mathrm{EqDMA}^{4}$} & 1 & $1.58 \pm 2.69$ & $28.0 \pm 15.16^{\mathrm{a}}$ & $0.7 \pm 3.15$ & $12.1 \pm 9.18^{b}$ & $0.4 \pm 1.01^{\mathrm{b}}$ & $1.2 \pm 5.84$ \\
\hline & 5 & $0.90 \pm 1.27$ & $22.3 \pm 9.96^{b}$ & $0.3 \pm 1.01$ & $16.9 \pm 8.86^{\mathrm{a}}$ & $1.5 \pm 0.82^{\mathrm{a}}$ & $1.3 \pm 4.10$ \\
\hline \multicolumn{8}{|l|}{ Effect } \\
\hline $\mathrm{D}$ & & $p=0.662$ & $p=0.622$ & $p=0.849$ & $p=0.225$ & $p=0.196$ & $p=0.529$ \\
\hline $\operatorname{Eq} 5^{\circ} \mathrm{C}$ & & $p=0.004$ & $p=0.750$ & $p=0.487$ & $p=0.236$ & $p=0.971$ & $p=0.159$ \\
\hline DMA & & $p=0.947$ & $p=0.810$ & $p=0.487$ & $p=0.788$ & $p=0.775$ & $p=0.034$ \\
\hline EqDMA & & $p=0.907$ & $p=0.020$ & $p=0.965$ & $p=0.036$ & $p=0.049$ & $p=0.688$ \\
\hline $\mathrm{D} * \mathrm{Eq} 5^{\circ} \mathrm{C}$ & & $p=0.438$ & $p=0.082$ & $p=0.453$ & $p=0.120$ & $p=0.471$ & $p=0.945$ \\
\hline
\end{tabular}


Table 3. Cont.

\begin{tabular}{lcccccc}
\hline & Bent & Fracture & Coiling & Swo-Det $^{5}$ & Knotted & No Tail \\
\hline & & \multicolumn{7}{c}{$\mathbf{( \% )}$} \\
\hline $\begin{array}{l}\mathrm{D}^{*} \mathrm{Eq5} \\
{ }^{\circ} \mathrm{C}^{*} \mathrm{DMA}\end{array}$ & $p=0.546$ & $p=0.607$ & $p=0.850$ & $p=0.992$ & $p=0.618$ & $p=0.904$ \\
$\begin{array}{l}\mathrm{D}^{*} \mathrm{Eq5} \\
{ }^{\circ} \mathrm{C}^{*} \mathrm{DMA}^{*}{ }_{\mathrm{Eq}} \mathrm{DMA}\end{array}$ & $p=0.514$ & $p=0.303$ & $p=0.268$ & $p=0.206$ & $p=0.469$ & $p=0.015$ \\
\hline
\end{tabular}

$\overline{1}$ dilution $(v / v) ;{ }^{2}$ equilibration at $5{ }^{\circ} \mathrm{C}$ (minutes); ${ }^{3}$ dimethylacetamide (\%); ${ }^{4}$ equilibration time with DMA (minutes); ${ }^{5}$ swollen/detached. $\mathrm{A}, \mathrm{B}$ Means within a column of each step of the freezing process with different superscripts are significantly different $(p<0.01)$. ${ }^{\mathrm{a}, \mathrm{b}}$ Means within a column of each step of the freezing process with different superscripts are significantly different $(p<0.05)$.

Table 4. Tail injuries in frozen common pheasant sperm while using two levels in each step (dilution, equilibration at $5{ }^{\circ} \mathrm{C}$, DMA concentration, equilibration time with DMA) of the process of freezing into pellets and the influence of the steps on the incidence of this damage (means $\pm \mathrm{SD}$ ).

\begin{tabular}{|c|c|c|c|c|}
\hline & & Looping & Coiling & No Head \\
\hline & & \multicolumn{3}{|c|}{$(\%)$} \\
\hline \multirow{2}{*}{$\mathrm{D}^{1}$} & $1: 2$ & $10.2 \pm 7.30$ & $0.2 \pm 0.51$ & $2.5 \pm 3.63$ \\
\hline & $1: 3$ & $12.8 \pm 8.20$ & $0.3 \pm 0.71$ & $2.4 \pm 3.07$ \\
\hline \multirow{2}{*}{$\mathrm{Eq} 5^{\circ} \mathrm{C}^{2}$} & 10 & $13.6 \pm 7.68$ & $0.4 \pm 0.78^{a}$ & $2.8 \pm 3.05$ \\
\hline & 30 & $9.2 \pm 7.51$ & $0.1 \pm 0.26^{b}$ & $2.1 \pm 3.61$ \\
\hline \multirow{2}{*}{$\mathrm{DMA}^{3}$} & 6 & $10.1 \pm 7.96^{\mathrm{B}}$ & $0.3 \pm 0.70$ & $2.4 \pm 3.30$ \\
\hline & 9 & $13.8 \pm 7.33^{\mathrm{A}}$ & $0.2 \pm 0.52$ & $2.5 \pm 3.36$ \\
\hline \multirow{2}{*}{ EqDMA $^{4}$} & 1 & $12.3 \pm 7.69$ & $0.2 \pm 0.47$ & $3.4 \pm 3.68$ \\
\hline & 5 & $11.2 \pm 8.03$ & $0.3 \pm 0.29$ & $1.9 \pm 2.92$ \\
\hline \multicolumn{5}{|l|}{ Effect } \\
\hline \multicolumn{2}{|l|}{$\mathrm{D}$} & $p=0.262$ & $p=0.844$ & $p=0.571$ \\
\hline \multicolumn{2}{|l|}{$\mathrm{Eq} 5^{\circ} \mathrm{C}$} & $p=0.081$ & $p=0.024$ & $p=0.084$ \\
\hline \multicolumn{2}{|l|}{ DMA } & $p=0.008$ & $p=0.844$ & $p=0.456$ \\
\hline \multicolumn{2}{|l|}{ EqDMA } & $p=0.980$ & $p=0.291$ & $p=0.103$ \\
\hline \multicolumn{2}{|c|}{$\mathrm{D}^{*} \mathrm{Eq} 5^{\circ} \mathrm{C}$} & $p=0.567$ & $p=0.414$ & $p=0.429$ \\
\hline \multicolumn{2}{|c|}{$\mathrm{D}^{*} \mathrm{Eq} 5^{\circ} \mathrm{C}^{*} \mathrm{DMA}$} & $p=0.940$ & $p=0.024$ & $p=0.700$ \\
\hline \multicolumn{2}{|c|}{$\mathrm{D}^{*} \mathrm{Eq} 5{ }^{\circ} \mathrm{C}^{*} \mathrm{DMA}{ }^{*} \mathrm{EqDMA}$} & $p=0.984$ & $p=0.097$ & $p=0.790$ \\
\hline
\end{tabular}

${ }^{1}$ dilution $(v / v) ;{ }^{2}$ equilibration at $5{ }^{\circ} \mathrm{C}$ (minutes); ${ }^{3}$ dimethylacetamide $(\%) ;{ }^{4}$ equilibration time with DMA (minutes). ${ }^{\mathrm{A}, \mathrm{B}}$ Means within a column of each step of the freezing process with different superscripts are significantly different $(p<0.01)$. ${ }^{a, b}$ Means within a column of each step of the freezing process with different superscripts are significantly different $(p<0.05)$.

The EqDMA affected the incidence of swollen/detached and knotted heads, and it was less detrimental when using one minute rather than five minutes (Table $3 ; p<0.05$ ). The EqDMA of one minute affected the occurrence of fractured cells (Table 3; $p<0.05$ ). A joint effect of $\mathrm{D}^{*} \mathrm{Eq} 5{ }^{\circ} \mathrm{C}^{*} \mathrm{DMA}$ was observed on the coiling of tails (Table $4 ; p<0.05$ ), and the combined effect of $\mathrm{D}^{*} \mathrm{Eq} 5{ }^{\circ} \mathrm{C}^{*} \mathrm{DMA}{ }^{*} \mathrm{EqDMA}$ was also observed in sperm with no tails (Table $3 ; p<0.05$ ).

\section{Discussion}

\subsection{Fresh Semen}

The quality of fresh semen is the first element to consider for a more promising performance with sperm that has undergone a freezing-thawing process. The fresh material in this study showed a high viability (91\%) compared to that in previous studies of pheasants, which reported mean values of $84-88 \%[20,21,34]$. The sperm mobility is also among the most critical aspects of sperm quality [9], which, in this survey, was in accordance with the findings of previous reports, which indicated absorbances of between 0.180 and 0.320 units $[23,34,35]$. According to our previous studies, the sperm concentration observed in this trial may be classified as highly concentrated, as evidenced by the values reported throughout the years, which varied from $5 \times 10^{9} / \mathrm{mL}$ to $12.5 \times 10^{9} / \mathrm{mL}[22,23,25,26,36]$. 


\subsection{The Extender}

As expected, the F-T-processed sperm showed a significant loss of viable and mobile cells compared with the fresh sperm. Many factors play key roles throughout the F-T process by acting on the integrity and performance of the sperm [37]. Some of these factors are intrinsic to the sperm, and others are linked to the F-T protocol. The individuation of a suitable F-T protocol for a specific species or breed implicates the testing of different variants and combinations in each step of the F-T protocol. The first question is which diluent to test; Saint-Jalme et al. [17] tested Lake's diluent [29] in wild pheasant species, and according to these authors, the extender had no effect on the viability or survival rate after the F-T process. Moreover, Tselutin et al. [33] reported high fertility rates in rooster sperm that was exposed to cryopreservation in pellets and a thawing method with a hotplate when employing Lake's diluent [29]. Therefore, we chose to test Lake's diluent [29] for the common pheasant. In agreement with Saint Jalme et al. [17], in this study, the diluent had no effect on the viability or the percentage of normal cells. However, the mobility $(p<0.01)$ and the recovered mobility $(p<0.05)$ were affected. Of the two dilution rates tested, the more diluted sperm (1:3) was more favourable, which was in agreement with the data reported previously [20]. The dilution of semen and, thus, the environment surrounding the sperm cells is essential in avoiding the rapid degradation to which the sperm is exposed in vitro due to its intense metabolism and the high proteolytic activity of the seminal enzymes $[1,38]$. For example, the fertilizing capacity of sperm in chickens is lost in less than one hour, and in guinea fowl, it takes less than half an hour [38]. In addition, a higher dilution rate was found to be associated with a higher fertility rate [39]. In the chicken [40] and in turkeys [41], more diluted sperm was reported to have better sperm quality parameters. On the contrary, other authors reported that lower dilution rates in the Pearl Guinea fowl were more favourable for the viability and maintenance of normal cells that were tested under short-term storage [42], and in chickens, more motile sperm were observed [43].

\subsection{The Freezing Process and the Cryoprotectant}

Sperm is prepared to withstand the thermal changes during the freezing process in the Eq5 ${ }^{\circ} \mathrm{C}$ step [3]. Cooling temperatures and rates may differ according to the species and to the cryoprotectant that is employed [1]. In this study, the cooling rate was chosen based on Tselutin et al. [33]; a decrease of $1^{\circ} \mathrm{C}$ every 18 seconds was used, which brought the semen from 18 to $5{ }^{\circ} \mathrm{C}$. The $\mathrm{Eq} 5{ }^{\circ} \mathrm{C}$ of ten minutes was more favourable for the viability of the cells, but higher numbers of bent sperm heads and coiling tails were observed. A higher viability was also noted in a previous study with the same Eq5 ${ }^{\circ} \mathrm{C}$, and, as in the present study, no effects on the mobility or recovered mobility were found [20]. In mammals, reports showed that among the most critical variables influencing the survival of sperm after the F-T process are the cooling and thawing rates [44]. In fact, during the cooling and freezing, the temperature decrease exposes the cells to biological damage, inducing them to adjust to osmotic and thermic changes [9,45-47]. The damages that cells may experience can be reversible, such as a temporary injury of the structure or the membrane permeability, or they can be permanent, which is evidenced by a lack of motility [48]. Therefore, to decrease the damage caused by intracellular ice and to regulate the transition induced by temperature variations, an intracellular cryoprotectant is needed [9,48]. However, if the cryoprotectant concentration is too high, it becomes toxic for the cells $[9,48]$. One of the most widely used cryoprotectants is DMA, which permits one to obtain high fertility rates, especially with pelleted sperm $[33,48,49]$. In this study, the effect of DMA was less deleterious for the mobility $(p<0.01)$ at a lower concentration $(6 \%)$. This result was confirmed by previous data that reported higher sperm mobility when using 6\% DMA [21]. The viability was not affected by the DMA in this study, while in a previous report, it was higher with $6 \%$ DMA [21]. Contrarily, a lower DMA concentration negatively affected the sperm viability in chickens [40], and a higher cryoprotectant concentration induced higher proportions of intact cell membranes [43]. In pheasants, a higher DMA concentration resulted in greater 
numbers of sperm without tails or with looping tails. The time employed to equilibrate the pheasant sperm with the cryoprotectant influenced the survival of these cells; 5 min was found to be more suitable. In a previous study that tested 5 and $30 \mathrm{~min}$ of equilibration with DMA, the period of 5 minutes was also shown to result in higher viability rates [21]; the same result was found in turkeys [41]. In chicken, the 30-minute DMA equilibration positively affected the sperm viability [40]. These differences highlight the complexity of the F-T process, in which many factors are involved; thus, it is necessary to find an equilibrium among all variants for the optimisation of the cryo-processing of pheasant sperm.

\subsection{The Protocols and the Evaluated Parameters}

The sperm's response to the evaluated parameters depended on the protocol. For example, the highest sperm viability was observed with the least diluted sperm, an Eq5 ${ }^{\circ} \mathrm{C}$ of $10 \mathrm{~min}, 9 \% \mathrm{DMA}$, and an EqDMA of $5 \mathrm{~min}$. The best mobility and recovered mobility were obtained with more diluted sperm, an Eq5 ${ }^{\circ} \mathrm{C}$ of $10 \mathrm{~min}, 6 \%$ DMA, and an EqDMA of 1 or $5 \mathrm{~min}$, or an Eq5 ${ }^{\circ} \mathrm{C}$ of $30 \mathrm{~min}, 6 \%$ DMA, and an EqDMA of 1 minute. Important knowledge has emerged with these results, even though this scenario occurred in vitro. To validate and test the real performance of the sperm that are treated according to specific protocols, an in vivo evaluation is undoubtedly the best approach. However, for example, in turkeys, to evaluate the capacity of toms to sire, when semen traits such as volume, sperm concentration, sperm viability, and membrane integrity were considered, no significant relationships with the offspring produced were observed [50]. Contrarily, sperm mobility has been demonstrated to have a significant correlation with paternity [50-53]. In fact, sperm mobility has been reported to be predictive of fertility [54,55]. In addition, it was demonstrated that a higher sperm concentration cannot counteract a lower sperm mobility in terms of the fertility rate [53,56], and according to Froman [52], every mobile sperm cell must be motile, but not every motile sperm cell is mobile. According to our experience $[25,57]$, the trait of sperm mobility may reflect AI outcomes in pheasants. Therefore, apparently, the parameters that are the least deleterious to the pheasant sperm that was frozen in pellets are the following: a dilution of 1:3, an Eq5 ${ }^{\circ} \mathrm{C}$ of $10 \mathrm{~min}, 6 \% \mathrm{DMA}$, and an EqDMA of $5 \mathrm{~min}$. However, further studies are needed in order to improve and individualise a complete and suitable protocol for the cryopreservation of pheasant sperm, including its thawing.

\section{Conclusions}

The pheasant sperm exhibited a high susceptibility to the damage caused by the methodology of freezing into pellets; however, the survival of the sperm reached $29 \%$, and the highest level of recovered mobility was $22 \%$.

Dilution and DMA affected the mobility, and the Eq5 ${ }^{\circ} \mathrm{C}$ and EqDMA influenced the sperm viability. The DMA and EqDMA influenced the cell integrity. The protocols that gave the best values exhibited higher dilution rates, an $\mathrm{Eq} 5^{\circ} \mathrm{C}$ of $10 \mathrm{~min}, 6 \% \mathrm{DMA}$, and an EqDMA of 1 or $5 \mathrm{~min}$.

Some applicable parameters for certain critical steps of the F-T process were isolated; however, further studies are needed in order to improve and complete a suitable protocol for the F-T process for pheasant sperm.

Author Contributions: Conceptualization, M.M.F.d.C., A.C. and A.S.; methodology, M.M.F.d.C., A.C., C.L., A.P., S.C. and N.I.; validation, M.M.F.d.C., A.C., S.C., S.S. and A.S.; formal analysis, A.C. and M.M.F.d.C.; investigation, M.M.F.d.C., A.C., C.L., A.P. and A.B.; data curation, M.M.F.d.C., A.C., C.L., A.P. and A.B.; writing—original draft preparation, A.C. and M.M.F.d.C.; writing-review and editing, M.M.F.d.C., A.C., S.S., C.R. and A.S.; supervision, M.M.F.d.C. and A.C.; project administration, M.M.F.d.C.; funding acquisition, S.C. and M.M.F.d.C. All authors have read and agreed to the published version of the manuscript.

Funding: This research project (PRIN prot. n. 2008RN9SCP_003) was funded by the Italian Ministry of University and Research, MUR. 
Institutional Review Board Statement: This study was approved by the Ethics Committee of Pisa University (Ref.: OPBA_26/2021) under article 2, paragraph 1, letter b of the Italian Legislative Decree n. 26/2014.

Informed Consent Statement: Not applicable.

Data Availability Statement: The data presented in this study are available on request from the corresponding author.

Acknowledgments: The authors thank Vito Cornacchia for providing the birds and the logistic support (bird/game farm "Allevamento Selvaggina Migliarino", Migliarino Pisano, Pisa, Italy).

Conflicts of Interest: The authors declare no conflict of interest.

\section{References}

1. Woelders, H. Cryopreservation of Avian Semen. In Cryopreservation and Freeze-Drying Protocols; Wolkers Willem, F., Oldenhof, H., Eds.; Springer: New York, NY, USA, 2021; pp. 379-399. ISBN 978-1-0716-0783-1.

2. Peña, F.J.; Saravia, F.; Núñez-Martínez, I.; Johannisson, A.; Wallgren, M.; Rodriguez Martinez, H. Do Different Portions of the Boar Ejaculate Vary in Their Ability to Sustain Cryopreservation? Anim. Reprod. Sci. 2006, 93, 101-113. [CrossRef]

3. Jovičić, M.; Chmelíková, E.; Sedmíková, M. Cryopreservation of Boar Semen. Czech. J. Anim. Sci. 2020, 65, 115-123. [CrossRef]

4. Holt, W.V. Fundamental Aspects of Sperm Cryobiology: The Importance of Species and Individual Differences. Theriogenology 2000, 53, 47-58. [CrossRef]

5. Lake, P.E.; Cherms, F.L.; Wishart, G.J. Effect of Aeration on the Fertilising Ability of Turkey Semen Stored for 48 Hours at 5 and 15 ${ }^{\circ} \mathrm{C}$ : A Study from the 33rd to the 47th Week of Age. Reprod. Nutr. Dev. 1984, 24, 147-153. [CrossRef]

6. Wishart, G.J. The Effect Of Continuous Aeration On The Fertility Of Fowl And Turkey Semen Stored Above $0{ }^{\circ}$ C. Br. Poult. Sci. 1981, 22, 445-450. [CrossRef]

7. Donoghue, A.M.; Wishart, G.J. Storage of Poultry Semen. Anim. Reprod. Sci. 2000, 62, S0378-S4320. [CrossRef]

8. Pegg, D.E. Principles of Cryopreservation. Methods Mol. Biol. 2015, 1257, 3-19. [CrossRef]

9. Blesbois, E. Freezing Avian Semen. Avian Biol. Res. 2011, 4. [CrossRef]

10. Blesbois, E. Current Status in Avian Semen Cryopreservation. World's Poult. Sci. J. 2007, 63, 213-222. [CrossRef]

11. Shanmugam, M.; Mahapatra, R. Pellet Method of Semen Cryopreservation: Effect of Cryoprotectants, Semen Diluents and Chicken Lines. Braz. Arch. Biol. Technol. 2019, 62. [CrossRef]

12. Kowalczy, A. The Effect of Cryopreservation Process on Morphology and Fertilising Ability of Japanese Quail (Coturnix Japonica) Spermatozoa. Cryo-Letters 2008, 29, 199-208.

13. Seigneurin, F.; Grasseau, I.; Chapuis, H.; Blesbois, E. An Efficient Method of Guinea Fowl Sperm Cryopreservation. Poult. Sci. 2013, 92, 2988-2996. [CrossRef] [PubMed]

14. Váradi, É.; Végi, B.; Liptói, K.; Barna, J. Methods for Cryopreservation of Guinea Fowl Sperm. PLoS ONE 2013, 8. [CrossRef]

15. Brown, M.E.; Singh, R.P.; Pukazhenthi, B.; Keefer, C.L.; Songsasen, N. Cryopreservation Effects on Sperm Function and Fertility in Two Threatened Crane Species. Cryobiology 2018, 82, 148-154. [CrossRef] [PubMed]

16. Sontakke, S.D.; Umapathy, G.; Sivaram, V.; Kholkute, S.D.; Shivaji, S. Semen Characteristics, Cryopreservation, and Successful Artificial Insemination in the Blue Rock Pigeon (Columba Livia). Theriogenology 2004, 62, 139-153. [CrossRef] [PubMed]

17. Saint Jalme, M.; Lecoq, R.; Seigneurin, F.; Blesbois, E.; Plouzeau, E. Cryopreservation of Semen from Endangered Pheasants: The First Step towards a Cryobank for Endangered Avian Species. Theriogenology 2003, 59, S0093-S0691. [CrossRef]

18. Zhang, Y.Y. Semen Characterization and Sperm Storage in Cabot's Tragopan. Poult. Sci. 2006, 85, 892-898. [CrossRef] [PubMed]

19. CITES Convention on International Trade in Endangered Species of Wild Fauna and Flora. Available online: https://cites.org/ eng/disc/text.php (accessed on 17 August 2021).

20. Marzoni, M.; Castillo, A.; Chiarini, R.; Bolognesi, P.G.; Romboli, I. Cryopreservation of Pheasant Semen: Effect of Dilution Ratio and Cooling Time on Spermatozoa Viability and Mobility. In Proceedings of the 1st Mediterranean Summit WPSA, Chalkidiki, Greece, 7-10 May 2008; Tserveni-Goussi, A., Yannakopoulos, A., Fortomaris, P., Arsenos, G., Sossidou, E., Eds.; University Studio Press: Thessaloniki, Greece, 2008; pp. 451-455.

21. Castillo, A.; Chiarini, R.; Bolognesi, P.G.; Romboli, I.; Marzoni, M. Cryopreservation of Pheasant Semen: Effect of DMA Concentration and Its Equilibration Time on Spermatozoa Viability and Mobility. In Proceedings of the 1st Mediterranean Summit of WPSA, Chalkidiki, Greece, 7-10 May 2008; Tserveni-Goussi, A., Yannakopoulos, A., Fortomaris, P., Arsenos, G., Sossidou, E., Eds.; University Studio Press: Thessaloniki, Greece, 2008; pp. 456-460.

22. Marzoni, M.; Castillo, A.; Romboli, I. Pheasant Semen Cryopreserved in Pellets: Effect of Drop Volume on Spermatozoa Viability and Mobility. In Proceedings of the Avian Biology Research, Norwich, UK, 7-8 July 2009.

23. Marzoni, M.; Castillo, A.; Romboli, I. In Vivo Responses of Cryopreserved Pheasant Semen. In Proceedings of the Avian Biology Research, Norwich, UK, 7-8 July 2009.

24. Castillo, A.; Romboli, I.; Marzoni, M. Cryopreserved Pheasant Semen Thawed by the Hotplate Method and Tested in Vivo. In Proceedings of the Avian Biology Research, Ede, The Netherlands, 30-31 August 2011. 
25. Marzoni, M.; Castillo, A.; Romboli, I. Hatchability of Pheasant Eggs Fertilised with Cryopreserved Semen from Dietary Manipulated Males. In Proceedings of the Avian Biology Research, Pisa, Italy, 13-15 June 2012.

26. Castillo, A.; Marzoni, M.; Romboli, I. Some Advices to Breed Common Pheasants Used as Donors of Good Quality Semen. In Proceedings of the Avian Biology Research, Norwich, UK, 7-8 July 2009.

27. Quinn, J.P.; Burrows, W.H. Artificial Insemination in Fowls. J. Hered. 1936, 27, 31-38. [CrossRef]

28. Castillo, A.; Lenzi, C.; Pirone, A.; Baglini, A.; Russo, C.; Soglia, D.; Schiavone, A.; Marzoni, M. In Vitro Traits and In Vivo Performance of Cryopreserved Sperms from Pheasants Fed Antioxidants Enriched Diet; 2021; Unpublished.

29. Lake, P.E. Observations on Freezing Fowl Spermatozoa in Liquid Nitrogen. In Proceedings of the International Congress of Animal Reproduction and Artificial Insemination, Milano, Italy, 26-30 June 1968.

30. Bakst, M.; Cecil, H.C. Techniques for Semen Evaluation, Semen Storage and Fertility Determination; Lab Manual ed.; Poultry Science Association: Champaign, IL, USA, 2007.

31. Bakst Murray, R.; Cecil, H.C. Sperm viability 1. Nigrosin/Eosin stain for determining liveydead and abnormal sperm counts. In Techniques for Semen Evaluation, Semen Storage, and Fertility Determination; The Poultry Science Association, Ed.; The Poultry Science Association: Champaign, IL, USA, 1997.

32. Froman, D.P.; McLean, D.J. Objective Measurement of Sperm Motility Based upon Sperm Penetration of Accudenz ${ }^{\circledR}$. Poult. Sci. 1996, 75, 776-784. [CrossRef]

33. Tselutin, K.; Seigneurin, F.; Blesbois, E. Comparison of Cryoprotectants and Methods of Cryopreservation of Fowl Spermatozoa. Poult. Sci. 1999, 78, 586-590. [CrossRef]

34. Castillo, A.; Marzoni, M.; Chiarini, R.; Romboli, I. Storage of Pheasant Semen: Some Aspects on Quality and Fertilising Ability. Anim. Repord. Sci. 2000, 60-61, 481-492.

35. Marzoni, M.; Castillo, A.; Chiarini, R.; Romboli, I. Comparison of Different Extenders for Holding Pheasant Semen. Ital. J. Anim. Sci. 2003, 2, 184-186.

36. Marzoni, M.; Castillo, A.; Chiarini, R.; Romboli, I. Effect of Vitamin E/Selenium Ratio on Mobility of Pheasant Spermatozoa. In Proceedings of the Avian Biology Research, Tours, France, 23 August 2010.

37. Watson, P.F. The Causes of Reduced Fertility with Cryopreserved Semen. Anim. Reprod. Sci. 2000, 60-61, 481-492. [CrossRef]

38. Santiago-Moreno, J.; Blesbois, E. Functional Aspects of Seminal Plasma in Bird Reproduction. Int. J. Mol. Sci. 2020, 21, 5664. [CrossRef] [PubMed]

39. Thelie, A.; Bailliard, A.; Seigneurin, F.; Zerjal, T.; Tixier-Boichard, M.; Blesbois, E. Chicken Semen Cryopreservation and Use for the Restoration of Rare Genetic Resources. Poult. Sci. 2019, 98, 447-455. [CrossRef]

40. Zaniboni, L.; Cassinelli, C.; Mangiagalli, M.G.; Gliozzi, T.M.; Cerolini, S. Pellet Cryopreservation for Chicken Semen: Effects of Sperm Working Concentration, Cryoprotectant Concentration, and Equilibration Time during in Vitro Processing. Theriogenology 2014, 82, 251-258. [CrossRef] [PubMed]

41. Iaffaldano, N.; Romagnoli, L.; Manchisi, A.; Rosato, M.P. Cryopreservation of Turkey Semen by the Pellet Method: Effects of Variables Such as the Extender, Cryoprotectant Concentration, Cooling Time and Warming Temperature on Sperm Quality Determined through Principal Components Analysis. Theriogenology 2011. [CrossRef] [PubMed]

42. Hudson, G.H.; Omprakash, A.v.; Premavalli, K. Effect of Semen Diluents, Dilution Rates and Storage Periods on Live and Abnormal Spermatozoa of Pearl Guinea Fowls. Asian J. Anim. Vet. Adv. 2016, 11, 411-416. [CrossRef]

43. Gliozzi, T.M.; Zaniboni, L.; Iaffaldano, N.; Cerolini, S. Spermatozoa DNA and Plasma Membrane Integrity after Pellet Optimized Processing for Cryopreservation in Meat Type Chicken Breeders. Br. Poult. Sci. 2017, 58, 578-584. [CrossRef] [PubMed]

44. Said, T.M.; Gaglani, A.; Agarwal, A. Implication of Apoptosis in Sperm Cryoinjury. Reprod. BioMed. Online 2010, $21,456-462$. [CrossRef] [PubMed]

45. Mazur, P.; Leibo, S.P.; Chu, E.H.Y. A Two-Factor Hypothesis of Freezing Injury. Evidence from Chinese Hamster Tissue-Culture Cells. Exp. Cell Res. 1972, 71, 345-355. [CrossRef]

46. Baust, J.G.; Gao, D.; Baust, J.M. Cryopreservation: An Emerging Paradigm Change. Organogenesis 2009, 5, 90-96. [CrossRef] [PubMed]

47. Ken, M.; Jason, P.A.; Janet, A.W.E.; Locksley, E.M. Life in the Frozen State; Barry, J.F., Nick, L., Erica, E.B., Eds.; CRC Press: Boca Raton, FL, USA, 2004.

48. Silyukova, Y.L.; Stanishevskaya, O.I.; Dementieva, N.V. The Current State of the Problem of in Vitro Gene Pool Preservation in Poultry. Vavilovskii Zhurnal Genet. Selektsii 2020, 24, 176-184. [CrossRef]

49. Santiago-Moreno, J.; Castaño, C.; Toledano-Díaz, A.; Coloma, M.A.; López-Sebastián, A.; Prieto, M.T.; Campo, J.L. Semen Cryopreservation for the Creation of a Spanish Poultry Breeds Cryobank: Optimization of Freezing Rate and Equilibration Time. Poult. Sci. 2011, 90, 2047-2053. [CrossRef]

50. Donoghue, A.M.; Sonstegard, T.S.; King, L.M.; Smith, E.J.; Burt, D.W. Turkey Sperm Mobility Influences Paternity in the Context of Competitive Fertilization. Biol. Reprod. 1999, 61, 422-427. [CrossRef]

51. Birkhead, T.R.; Martínez, J.G.; Burke, T.; Froman, D.P. Sperm Mobility Determines the Outcome of Sperm Competition in the Domestic Fowl. Proc. Biol. Sci. 1999, 266. [CrossRef]

52. Froman, D.P. Application of the Sperm Mobility Assay to Primary Broiler Breeder Stock. J. Appl. Poult. Res. 2006, 15, 280-286. [CrossRef] 
53. King, L.M.; Kirby, J.D.; Froman, D.P.; Sonstegard, T.S.; Harry, D.E.; Darden, J.R.; Marini, P.J.; Walker, R.M.; Rhoads, M.L.; Donoghue, A.M. Efficacy of Sperm Mobility Assessment in Commercial Flocks and the Relationships of Sperm Mobility and Insemination Dose with Fertility in Turkeys. Poult. Sci. 2000, 79, 1797-1802. [CrossRef]

54. King, L.M.; Holsberger, D.R.; Donoghue, A.M. Correlation of CASA Velocity and Linearity Parameters with Sperm Mobility Phenotype in Turkeys. J. Androl. 2000, 21. [CrossRef]

55. Froman, D.P.; Feltmann, A.J. Sperm Mobility: A Quantitative Trait of the Domestic Fowl (Gallus Domesticus). Biol. Reprod. 1998, 58, 379-384. [CrossRef]

56. Froman, D.P.; Feltmann, A.J.; Mclean, D.J. Increased Fecundity Resulting from Semen Donor Selection Based Upon in Vitro Sperm Motility. Poult. Sci. 1997, 76, 73-77. [CrossRef] [PubMed]

57. Castillo, A.R.I.M.M. Preliminary Investigation on Fertility and Hatchability by the Use of Cryopreserved Cock Semen. Avian Biol. Res. 2010. [CrossRef] 